\title{
TRADE, NON-SCALE GROWTH AND UNEVEN DEVELOPMENT
}

$\operatorname{AUTHOR}(S)$ :

Sasaki, Hiroaki

CITATION:

Sasaki, Hiroaki. TRADE, NON-SCALE GROWTH AND UNEVEN

DEVELOPMENT. Metroeconomica 2011, 62(4): 691-711

\section{ISSUE DATE:}

2011-08-28

URL:

http://hdl.handle.net/2433/197370

\section{RIGHT:}

This is the peer reviewed version of the following article: Sasaki, H. (2011), TRADE, NON-SCALE GROWTH AND UNEVEN DEVELOPMENT. Metroeconomica, 62: 691-711, which has been published in final form at

http://dx.doi.org/10.1111/j.1467-999x.2011.04135.x; この論文は出版社版でありません。引用の際には出版社版をご確 認ざ利用ください。;This is not the published version. Please cite only the published version. 


\title{
Trade, Non-Scale Growth, and Uneven Development*
}

\author{
Hiroaki SASAKI ${ }^{\dagger}$ \\ Graduate School of Economics, Kyoto University
}

\begin{abstract}
This paper investigates the relationship between trade and economic development using a two-country, non-scale-growth model. Depending on the share of the expenditure for manufactured goods, we obtain two different results with regard to long-run production patterns. Whether or not the follower country can catch up with the leader country in the long run depends on two factors: (1) the patterns of production in both countries and (2) the measure of economic welfare that is used, that is, per capita income or per capita consumption.
\end{abstract}

Keywords: international trade; non-scale growth; uneven development JEL Classification: F10; F43; O11; O41

*I would like to thank three anonymous referees for their suggestions and helpful comments. I am grateful to KAKENHI (21730182) for financial support. The usual disclaimer applies.

${ }^{\dagger}$ Address for correspondence: Hiroaki Sasaki. Graduate School of Economics, Kyoto University, YoshidaHonmachi, Sakyo-ku, Kyoto 606-8501, Japan; e-mail: sasaki@econ.kyoto-u.ac.jp 


\section{Introduction}

Does the world income distribution converge? According to the neoclassical growth model, even if there are differences in the initial capital stock, per capita incomes in all countries converge to the same level if the parameters of the countries are identical (Solow (1956)).

However, the reality seems to be different from what the neoclassical growth theory predicts. For example, by using Penn World Table, Acemoglu and Ventura (2002) and Felbermayr (2007) show that the world income distribution has been relatively stable whereas Quah (1996) and Epstein et al. (2007) show that the world income distribution has diverged. Thus, empirical evidence on convergence is questionable.

Such disparities in the income level can be said to imply uneven development. There are many theoretical studies that investigate uneven development in the context of NorthSouth trade (Molana and Vines (1989), Conway and Darity (1991), Dutt (1996, 2002), and Sarkar (2001, 2009)). These studies emphasize that uneven development is inevitable given North-South asymmetries in economic structures such as the patterns of production, income distribution, and consumption.

It is true that economic structures differ between developed and developing countries and North-South trade models are appropriate for analyzing such a situation. However, it is also important to consider whether or not the level of per capita income in each country would equalize if the asymmetries in economic structures disappear.

To our understanding, Krugman's (1981) model is suitable for such analysis. Using a two-country model with constant-returns-to-scale agricultural and increasing-returns-toscale manufacturing sectors, he shows that given different initial endowments of capital stock, each country experiences a different path of economic development even if both countries have the same technology.

Nevertheless, Krugman's model has some problems. In his model, the rate of capital accumulation is equal to the rate of profit. In the long run, the rate of profit is zero, and hence, the capital accumulation stops, which implies that the long-run economic growth rate is zero even if the economy completely specializes in manufacturing. Moreover, along the transitional dynamics, the rate of profit can be negative. He also assumes that population growth is zero. In reality, population growth is not zero and economic growth is not zero.

In addition, his analysis is not adequate. Uneven development in Krugman's model is the polarization that the capital-rich country can industrialize whereas the capital-poor country cannot, and that is all there is to this. In other words, a detailed analysis has not been conducted with regard to the income gap between the countries and each country's income per capita growth rate. 
Based on these observations, we extend Krugman's model to the non-scale-growth case. ${ }^{1}$ In the scale-growth model, the growth rate of output per capita along the balanced growth path (BGP) depends positively on the size of the population: the larger the size of the population, the faster the growth of the country. This, however, seems counterfactual. In the non-scale-growth model, in contrast, the growth rate of output per capita depends positively on the rate of population growth, and not on the size of the population: the higher the growth rate of population, the faster the growth of the country. We assume that the production function in manufacturing exhibits increasing returns to scale but the extent is not so large: the elasticity of output with respect to capital stock is less than unity. In addition, we assume that the population growth rate is strictly positive. These assumptions ensure that in our model, not only the growth rate of the economy but also the growth rate of real income per capita is strictly positive in the long run.

Our idea is based on the work of Christiaans (2008). He develops a small-open-economy, non-scale-growth model in which there exist a constant-returns-to-scale agricultural sector and an increasing-returns-to-scale manufacturing sector, and examines the transitional dynamics toward the long-run equilibrium. ${ }^{2}$ He introduces the rest of the world whose structures except for population growth are identical with the home economy, and assumes that the rest of the world is already on the BGP. Our model extends Christiaans' model to the two-country case.

Using the model, we mainly investigate the following two issues: (i) the terms in which uneven development is defined-uneven development in terms of income or uneven development in terms of consumption - and (ii) the evolution of uneven development with the transition from autarky to free trade. Here, we briefly explain the second issue. In the usual trade theory, the transition from autarky to free trade is desirable because it improves welfare. In this respect, the criterion used is real income per capita or utility (real consumption per capita). However, as will be shown later, it is possible that at first, the transition from autarky to free trade decreases real income and real consumption. Nevertheless, it is possible that with the passage of time, the real per capita consumption under free trade exceeds that under autarky. In such cases, we need to examine the dynamic gains from trade along with the static gains from trade. ${ }^{3}$ It is possible that there exist gains from trade in the long run whereas there exist no gains from trade in the short run.

The remainder of the paper is organized as follows. Section 2 presents our model and

\footnotetext{
${ }^{1}$ For systematic expositions with regard to non-scale growth and scale effects, see Jones (1999) and Christiaans (2004).

${ }^{2}$ Christiaans (2008) uses learning-by-doing to express increasing returns to scale. Sasaki (2008) introduces human capital accumulation into Christiann's (2008) model.

${ }^{3}$ For static and dynamic gains from trade, see also Baldwin (1992), Mazumdar (1996), and Redding (1999).
} 
examines the BGP and transitional dynamics under autarky. Section 3 classifies the production patterns under free trade. Section 4 investigates the BGP growth rates under free trade. Section 5 analyzes the transitional dynamics under free trade. Section 6 investigates the uneven development of income and consumption, and compares autarky with free trade. Section 7 concludes the paper.

\section{Model}

Consider a world that consists of Home (leader country) and Foreign (follower country). Both countries produce homogeneous manufactured and agricultural goods. The manufactured good is used for consumption and investment while the agricultural good is used only for consumption.

\subsection{Production}

Firms produce manufactured goods $X_{i}^{M}$ with labor input $L_{i}^{M}$ and capital stock $K_{i}$ and produce agricultural goods $X_{i}^{A}$ with only labor input $L_{i}^{A}$. Here, $i=1$ and $i=2$ denote Home and Foreign, respectively. Both countries have the same production functions, which are specified as follows:

$$
\begin{aligned}
X_{i}^{M} & =A_{i} K_{i}^{\alpha}\left(L_{i}^{M}\right)^{1-\alpha}, \quad \text { where } A_{i}=K_{i}^{\beta} \\
& =K_{i}^{\alpha+\beta}\left(L_{i}^{M}\right)^{1-\alpha}, \quad 0<\alpha<1,0<\beta<1, \alpha+\beta<1, \\
X_{i}^{A} & =L_{i}^{A} .
\end{aligned}
$$

Here, $A_{i}$ in equation (1) expresses an externality associated with capital accumulation, which captures the learning-by-doing effect à la Arrow (1962). Substituting $A_{i}$ into equation (1), we obtain equation (2), which shows that manufacturing production is increasing returns to scale and $\beta$ corresponds to the extent of the increasing returns. Equation (3) shows that agricultural production is constant returns to scale.

Suppose that labor supply is equal to population and that population is fully employed. Moreover, suppose that population grows at a constant rate $n$ and initial population is unity in each country: $L=L_{i}^{M}(t)+L_{i}^{A}(t)=e^{n t}, n>0$. Note that we assume that both countries are symmetric in terms of total population, that is, $L_{1}=L_{2}=L$ and $n_{1}=n_{2}=n$. Even if the initial population levels are different, we can obtain similar results. However, $n_{1}=n_{2}$ is necessary for the existence of the BGP under free trade.

Let $p_{i}$ denote the price of manufactured goods relative to agricultural goods. Then, the 
profits of manufacturing and agricultural firms are, respectively, given by $\pi_{i}^{M}=p_{i} X_{i}^{M}-$ $w_{i} L_{i}^{M}-p_{i} r_{i} K_{i}$ and $\pi_{i}^{A}=X_{i}^{A}-w_{i} L_{i}^{A}$, where $w_{i}$ denotes wage in terms of agricultural goods and $r_{i}$ denotes the profit rate.

From the profit-maximizing conditions, we obtain the following relations:

$$
\begin{aligned}
p_{i} \partial X_{i}^{M} / \partial L_{i}^{M} & =w_{i}=1 \\
\partial X_{i}^{M} / \partial K_{i} & =r_{i} \text { with } A_{i} \text { given } .
\end{aligned}
$$

From equation (4), we find that wage is unity as long as agricultural production is positive. Note that we assume a Marshallian externality in deriving equation (5): profit-maximizing firms regard $A_{i}$ as exogenously given. Accordingly, firms do not internalize the effect of $A_{i}$.

\subsection{Consumption}

For simplification, we make the classical assumption that wage income and profit income are entirely devoted to consumption and saving, respectively. Let us define real consumption per capita $c_{i}$ as $c_{i}=C_{i} / L=\left(C_{i}^{M}\right)^{\gamma}\left(C_{i}^{A}\right)^{1-\gamma} / L$, where $C_{i}$ denotes the economy-wide real consumption. In this case, a fraction $\gamma$ of wage income is spent on $C_{i}^{M}$ and the rest $1-\gamma$ is spent on $C_{i}^{A}$. The same assumption is also adopted by Krugman (1981) and Christiaans (2008):

$$
\begin{aligned}
p_{i} C_{i}^{M} & =\gamma w_{i} L, \\
C_{i}^{A} & =(1-\gamma) w_{i} L .
\end{aligned}
$$

Moreover, the following relationship between real investment $I$ and saving holds: $p_{i} I_{i}=$ $p_{i} r_{i} K_{i}$. From this equation, the rate of capital accumulation leads to

$$
\dot{K}_{i} / K_{i}=r_{i}
$$

That is, the rate of capital accumulation is equal to the rate of profit. A dot over a variable denotes the time derivative of the variable (e.g., $\dot{K}_{i} \equiv d K_{i} / d t$ ).

\subsection{Equilibrium under autarky}

Under autarky, both goods have to be produced. The market-clearing conditions are as follows: $X_{i}^{M}=C_{i}^{M}+I_{i}$ and $X_{i}^{A}=C_{i}^{A}$. Note that we have $w_{i}=1$ under autarky. From the market-clearing condition for manufactured goods, we obtain $p_{i}$, which is used to derive 
each sector's employment share: $L_{i}^{M} / L=\gamma$ and $L_{i}^{A} / L=1-\gamma$. Therefore, under autarky, each sector's employment share is constant.

Under autarky, the relative price of manufactured goods is given by

$$
p_{i}=(\gamma L)^{\alpha} /\left[(1-\alpha) K_{i}^{\alpha+\beta}\right]
$$

If $K_{1}>K_{2}$, then we have $p_{1}<p_{2}$. This means that if $K_{1}>K_{2}$, then Home has a comparative advantage in manufacturing while Foreign has a comparative advantage in agriculture.

Let us derive the BGP under autarky. Along the BGP, the rate of capital accumulation is constant. The rate of capital accumulation is equal to the rate of profit, which is given from equation (5) by $r_{i}=\alpha K_{i}^{\alpha+\beta-1}(\gamma L)^{1-\alpha}$. From this, the BGP growth rates of $K_{i}$ and $p_{i}$ are, respectively, given by

$$
\begin{aligned}
& g_{K_{i}}^{*}=\phi n>0, \\
& g_{p_{i}}^{*}=-(\phi-1) n<0, \quad \text { where } \phi \equiv(1-\alpha) /(1-\alpha-\beta)>1 .
\end{aligned}
$$

The rate of capital accumulation is positive and proportionate to the population growth, and the relative price of manufactured goods is decreasing at a constant rate.

Considering the BGP growth rate of capital stock, we introduce a new variable (scaleadjusted capital stock): $k_{i} \equiv K_{i} / L^{\phi}$. The dynamics of the scale-adjusted capital stock are given by

$$
\dot{k}_{i}=\alpha \gamma^{1-\alpha} k_{i}^{\alpha+\beta}-\phi n k_{i}
$$

The steady state is a situation where $\dot{k}_{i}=0$, from which we obtain

$$
k_{1}^{*}=k_{2}^{*}=\left\{\left[\alpha \gamma^{1-\alpha} /(\phi n)\right]\right\}^{\frac{1}{1-\alpha-\beta}} .
$$

The steady state is stable because we have $d \dot{k}_{i} /\left.k_{i}\right|_{k_{i}=k_{i}^{*}}=-k_{i}^{*}\left[(1-\alpha-\beta) \alpha \gamma^{1-\alpha}\left(k_{i}^{*}\right)^{\alpha+\beta-2}+\phi n\right]<$ 0 .

\section{Classification of the production patterns under free trade}

From the viewpoint of Home, the following four patterns are sufficient for our purpose.

Case 1 Both countries produce both goods, that is, both countries diversify.

Case 2 Home completely specializes in manufacturing while Foreign completely specializes in agriculture. 
Case 3 Home diversifies while Foreign completely specializes in agriculture.

Case 4 Home completely specializes in manufacturing while Foreign diversifies.

\subsection{Case 1: Both countries diversify}

In Case 1, the market-clearing conditions for both goods are as follows:

$$
\begin{aligned}
X_{1}^{M}+X_{2}^{M} & =C_{1}^{M}+C_{2}^{M}+I_{1}+I_{2}, \\
X_{1}^{A}+X_{2}^{A} & =C_{1}^{A}+C_{2}^{A} .
\end{aligned}
$$

Rewriting equation (14) with equations (5), (6), and $I_{i}=r_{i} K_{i}$, we have

$$
p\left(X_{1}^{M}+X_{2}^{M}\right)=\gamma\left(w_{1}+w_{2}\right) L+p \alpha\left(X_{1}^{M}+X_{2}^{M}\right) .
$$

From equation (4), we obtain $L_{i}^{M}=\left[p(1-\alpha) K_{i}^{\alpha+\beta}\right]^{\frac{1}{\alpha}}$, which is substituted into equation (2) to get $X_{i}^{M}=K_{i}^{\alpha+\beta}\left[p(1-\alpha) K_{i}^{\alpha+\beta}\right]^{\frac{1-\alpha}{\alpha}}$. Substituting this expression into equation (16), we obtain the price of manufactured goods:

$$
p^{\frac{1}{\alpha}}=2 \gamma L /\left[(1-\alpha)^{\frac{1}{\alpha}}\left(K_{1}^{\frac{\alpha+\beta}{\alpha}}+K_{2}^{\frac{\alpha+\beta}{\alpha}}\right)\right] .
$$

Substituting equation (17) into $L_{i}^{M}=\left[p(1-\alpha) K_{i}^{\alpha+\beta}\right]^{\frac{1}{\alpha}}$, we obtain the share of manufacturing employment in both countries:

$$
\begin{aligned}
& \theta_{1}^{M} \equiv L_{1}^{M} / L=2 \gamma /\left[1+\left(K_{2} / K_{1}\right)^{\frac{\alpha+\beta}{\alpha}}\right], \\
& \theta_{2}^{M} \equiv L_{2}^{M} / L=2 \gamma /\left[1+\left(K_{1} / K_{2}\right)^{\frac{\alpha+\beta}{\alpha}}\right] .
\end{aligned}
$$

As stated above, the rate of capital accumulation is equal to the rate of profit (see equation (8)). In this case, the rate of profit is given by $r_{i}=\alpha K_{i}^{\alpha+\beta-1}\left(\theta_{i}^{M} L\right)^{1-\alpha}$, and consequently,

$$
\dot{K}_{i} / K_{i}=\alpha K_{i}^{\alpha+\beta-1}\left(\theta_{i}^{M} L\right)^{1-\alpha}
$$

For both countries' diversification to last, additional conditions are required. First, we assume that both countries' capital stocks are strictly positive, that is, $K_{1}>0$ and $K_{2}>0$. Second, let us express Home's agricultural output as a function of $K_{1}$ and $K_{2}$ :

$$
X_{1}^{A}=\left\{1-\left(2 \gamma /\left[1+\left(K_{2} / K_{1}\right)^{\frac{\alpha+\beta}{\alpha}}\right]\right)\right\} L
$$


The condition $X_{1}^{A}>0$ is given by

$$
\left(K_{2} / K_{1}\right)^{\frac{\alpha+\beta}{\alpha}}>2 \gamma-1 .
$$

When both $K_{1}>0$ and $K_{2}>0$, equation (22) necessarily holds if $\gamma \leq 1 / 2$. That is, if the expenditure share for manufactured goods is less than or equal to half, then agricultural output is strictly positive, which means that both countries always diversify. If, on the other hand, $\gamma>1 / 2$, we can rewrite equation (22) as follows:

$$
K_{2}>(2 \gamma-1)^{\frac{\alpha}{\alpha+\beta}} K_{1}
$$

This means that if $K_{1}$ and $K_{2}$ satisfy equation (23), Home's agricultural output is strictly positive. In the same way, we can derive the condition that Foreign's agricultural output is strictly positive when $\gamma>1 / 2$ as follows:

$$
K_{2}<K_{1} /(2 \gamma-1)^{\frac{\alpha}{\alpha+\beta}}
$$

\subsection{Case 2: Home produces only manufactured goods while Foreign produces only agricultural goods}

In Case 2, only Home accumulates capital stock and the market-clearing conditions for both goods are as follows: $X_{1}^{M}=C_{1}^{M}+C_{2}^{M}+I_{1}$ and $X_{2}^{A}=C_{1}^{A}+C_{2}^{A}$. Using these equations, we obtain the terms of trade:

$$
p=\gamma L /\left[(1-\alpha)(1-\gamma) X_{1}^{M}\right]
$$

The rate of capital accumulation is given by

$$
\dot{K}_{1} / K_{1}=\alpha K_{1}^{\alpha+\beta-1} L^{1-\alpha}
$$

\subsection{Case 3: Home diversifies while Foreign produces only agricultural goods}

In Case 3, only Home accumulates capital stock and the market-clearing conditions for both goods are as follows: $X_{1}^{M}=C_{1}^{M}+C_{2}^{M}+I_{1}$ and $X_{1}^{A}+X_{2}^{A}=C_{1}^{A}+C_{2}^{A}$. Using these equations, we obtain the terms of trade:

$$
p=2 \gamma L /\left[(1-\alpha) X_{1}^{M}\right]
$$


With $p$ now determined, we can obtain the share of manufacturing employment in Home:

$$
\theta_{1}^{M}=2 \gamma
$$

For $0<\theta_{1}^{M}<1$ to hold, we need

$$
\gamma<1 / 2
$$

The rate of capital accumulation is given by

$$
\dot{K}_{1} / K_{1}=\alpha K_{1}^{\alpha+\beta-1}(2 \gamma L)^{1-\alpha}
$$

\subsection{Case 4: Home produces only manufactured goods while Foreign diversifies}

In Case 4, both countries accumulate capital stock. The market-clearing conditions for both goods are as follows: $X_{1}^{M}+X_{2}^{M}=C_{1}^{M}+C_{2}^{M}+I_{1}+I_{2}$ and $X_{2}^{A}=C_{1}^{A}+C_{2}^{A}$. From this, the terms of trade are given by

$$
p=\gamma L /\left\{(1-\alpha)\left[(1-\gamma) X_{1}^{M}+X_{2}^{M}\right]\right\}
$$

Rewriting equation (31) leads to

$$
(1-\alpha)^{\frac{1}{\alpha}} K_{2}^{\frac{\alpha+\beta}{\alpha}} p^{\frac{1}{\alpha}}=\gamma L-(1-\alpha)(1-\gamma) K_{1}^{\alpha+\beta} L^{1-\alpha} p .
$$

Equation (32) is an equation that determines $p$. Although we cannot find $p$ explicitly, we can see that $p$ is uniquely determined: ${ }^{4}$

$$
p=p\left(K_{1}, K_{2}, L\right)
$$

In this case, the rate of capital accumulation is given by

$$
\begin{aligned}
& \dot{K}_{1} / K_{1}=\alpha K_{1}^{\alpha+\beta-1} L^{1-\alpha}, \\
& \dot{K}_{2} / K_{2}=\alpha(1-\alpha)^{\frac{1-\alpha}{\alpha}} p^{\frac{1-\alpha}{\alpha}} K_{2}^{\frac{\beta}{\alpha}} .
\end{aligned}
$$

\footnotetext{
${ }^{4}$ Let us consider the left-hand and right-hand sides of equation (32) to be the functions of $p$. Then, the left-hand side is an increasing function of $p$ that passes through the origin and the right-hand side is a straight line with a negative slope and a positive intercept. From this, $p$ is determined by the intersection of the two functions.
} 
Note that $p$ in equation (35) should be replaced by $p$ that is determined through equation (33).

\section{Long-run growth rates}

\subsection{BGP growth rates of capital stock and terms of trade}

We derive the BGP growth rates of capital stock and the terms of trade in Cases 1-4.

Along the BGP, the rate of profit is constant. Considering that the rate of profit in Cases $1-4$ will be constant, we obtain the following result: ${ }^{5}$

$$
g_{K_{1}}^{*}=g_{K_{2}}^{*}=\phi n>0 .
$$

Note that in Cases 2 and 3 where Foreign completely specializes in agriculture, we have $g_{K_{2}}^{*}=0$ because no capital is accumulated.

Moreover, in every case, the BGP growth rate of the terms of trade leads to

$$
g_{p}^{*}=-(\phi-1) n<0
$$

Therefore, if there exists a BGP in each case, then the BGP growth rates of the endogenous variables are the same as those obtained under autarky.

\subsection{Per capita income growth and per capita consumption growth}

We use the real income per capita and real consumption per capita as measures of economic welfare. To obtain these measures, we need to define the price index. In the following analysis, we use the consumer price index. Let $p_{c}$ denote the consumer price index that is consistent with the expenditure-minimizing problem. ${ }^{6}$ Then, the price index is given by $p_{c}=p^{\gamma}{ }^{7}$

Let $y_{i, A}$ and $y_{i, M}$ denote the real income per capita when the economy completely specializes in agriculture and the real income per capita when the economy completely specializes in manufacturing, respectively. Then, we have $y_{i, A}=X_{i}^{A} /\left(p_{c} L\right)=1 / p^{\gamma}$ and $y_{i, M}=$

\footnotetext{
${ }^{5}$ For the derivation of the BGP growth rates in Case 4, see Appendix A, which is available on request.

${ }^{6}$ For the issue of which deflator should be used when calculating real income, see Temple (2005). Temple (2005) points out that in calculating real national income in an open economy setting, there is an important distinction between a GDP price index and a cost-of-living index because the structure of consumption and that of production can be different.

${ }^{7}$ Strictly speaking, we have $p_{c}=\gamma^{-\gamma}(1-\gamma)^{-(1-\gamma)} p^{\gamma}$. However, we use $p_{c}=p^{\gamma}$ because the constant terms have no effect on our results.
} 
$\left(p X_{i}^{M}\right) /\left(p_{c} L\right)=\left(p^{1-\gamma} X_{i}^{M}\right) / L$. Remember that the BGP growth rate of $K$ and that of $p$ are $g_{K}^{*}=\phi n$ and $g_{p}^{*}=-(\phi-1) n$, respectively. Using these growth rates, we can obtain the following growth rates of real income per capita: $g_{y_{i, A}}^{*}=g_{y_{i, M}}^{*}=\gamma(\phi-1) n>0$.

Let $y_{i, D}$ denote the real income per capita when the economy diversifies. Then, we have $y_{i, D}=\left(p X_{i}^{M}+X_{i}^{A}\right) /\left(p_{c} L\right)$. Given that along the BGP, each sector's employment share is constant, we find that the growth rates of $p X_{i}^{M}$ and $X_{i}^{A}$ under diversification are equal to the growth rates of $p X_{i}^{M}$ and $X_{i}^{A}$ under complete specialization, respectively. Accordingly, the growth rate of $y_{i, D}$ is equal to the growth rates of $y_{i, A}$ and $y_{i, M}$ :

$$
g_{y_{i, D}}^{*}=g_{y_{i, A}}^{*}=g_{y_{i, M}}^{*}=\gamma(\phi-1) n>0 .
$$

Therefore, the BGP growth rate of real income per capita is equal in every case.

We now focus on real consumption per capita. In our model, consumption consists of only wage income, and hence, $c_{i}$ is equal to real wage in terms of the consumer price index, that is, $c_{i}=w_{i} / p_{c}$. As long as both goods are produced, we have $w=1$, from which we obtain $c_{i}=1 / p_{c}$ under autarky and under diversification in free trade. Under complete specialization in manufacturing, we obtain $c_{i}=w_{i} / p_{c}=(1-\alpha) p K_{i}^{\alpha+\beta} L^{-\alpha} / p_{c}$. Because the numerator is constant in the long-run equilibrium, the BGP growth rate of real consumption per capita is equal to the absolute value of the rate of change in the consumer price index, and therefore, is equal to the growth rate of real income per capita: ${ }^{8}$

$$
g_{c_{i}}^{*}=g_{y_{i, A}}^{*}=g_{y_{i, M}}^{*}=g_{y_{i, D}}^{*}=\gamma(\phi-1) n>0 .
$$

The result that a country specializing in a low-growth sector (agriculture in our model) can attain the same growth rate as a country specializing in a high-growth sector (manufacturing in our model) is also shown in Felbermayr (2007). ${ }^{9}$

\section{Transitional dynamics}

\subsection{Dynamical systems of scale-adjusted variables}

The above analysis concerns a situation where both countries' production patterns are fixed to their corresponding initial patterns. In what follows, we analyze the transitional dynamics

\footnotetext{
${ }^{8}$ Therefore, the growth rate of real consumption per capita is identical to the growth rate of indirect utility.

${ }^{9}$ A similar result is obtained in Sasaki (2001). He builds a non-scale growth, North-South economic development model, and shows that along the BGP, both countries grow at the same rate but per capita incomes grow at different rates because of the differences in population growth.
} 
of both countries with initial endowments of capital stock being given historically. Here, we assume that both countries already engage in free trade at the initial time.

The dynamical equations of scale-adjusted variables for each case can be written as follows: ${ }^{10}$

[Case 1] $\dot{k}_{1}=\alpha k_{1}^{\alpha+\beta}\left\{2 \gamma /\left[1+\left(k_{2} / k_{1}\right)^{\frac{\alpha+\beta}{\alpha}}\right]\right\}^{1-\alpha}-\phi n k_{1}, \dot{k}_{2}=\alpha k_{2}^{\alpha+\beta}\left\{2 \gamma /\left[1+\left(k_{1} / k_{2}\right)^{\frac{\alpha+\beta}{\alpha}}\right]\right\}^{1-\alpha}-$ $\phi n k_{2}, k_{2}>(2 \gamma-1)^{\frac{\alpha}{\alpha+\beta}} k_{1}, k_{2}<k_{1} /(2 \gamma-1)^{\frac{\alpha}{\alpha+\beta}}$, and $\gamma>1 / 2$.

[Case 2] $\dot{k}_{1}=\alpha k_{1}^{\alpha+\beta}-\phi n k_{1}$.

[Case 3] $\dot{k}_{1}=\alpha(2 \gamma)^{1-\alpha} k_{1}^{\alpha+\beta}-\phi n k_{1}$ and $\gamma<1 / 2$.

[Case 4] $\dot{k}_{1}=\alpha k_{1}^{\alpha+\beta}-\phi n k_{1}, \dot{k}_{2}=\alpha(1-\alpha)^{\frac{1-\alpha}{\alpha}} \pi^{\frac{1-\alpha}{\alpha}} k_{2}^{\frac{\alpha+\beta}{\alpha}}-\phi n k_{2}$, and $(1-\alpha)^{\frac{1}{\alpha}} k_{2}^{\frac{\alpha+\beta}{\alpha}} \pi^{\frac{1}{\alpha}}=\gamma-(1-$ $\alpha)(1-\gamma) k_{1}^{\alpha+\beta} \pi$, where $\pi \equiv p L^{\phi-1}=\pi\left(k_{1}, k_{2}\right), \pi_{k_{i}}<0(i=1,2)$.

In the phase diagram that will be introduced later, the area composed of the two equalities of Case 1 forms a diversification cone. As long as a combination of $k_{1}$ and $k_{2}$ is inside the cone, both countries diversify. However, if a combination of $k_{1}$ and $k_{2}$ is outside the cone, one country's agricultural output becomes zero and the country completely specializes in manufacturing while the other country diversifies.

Let us explain Case 4 in detail. Because the terms of trade $p$ continue to decline at a constant rate along the BGP, we introduce a new variable $\pi \equiv p L_{2}^{\varepsilon}$ (scale-adjusted terms of trade). In the steady state in this case, $\dot{k}_{1}=0, \dot{k}_{2}=0$, and the rewritten form of equation (32) have to be satisfied simultaneously. However, as a later analysis with phase diagram will show, such a situation does not exist. The loci of $\dot{k}_{1}=0$ and $\dot{k}_{2}=0$ do not intersect. Nevertheless, as the later analysis with phase diagram will show, we can know the long-run situation. In the long run, $k_{1}$ converges to a value determined by $\dot{k}_{1}=0, k_{2}$ asymptotically converges to zero, and $\pi$ will be constant.

\subsection{Transition to an industrial or a non-industrial country}

As stated above, the dynamical systems differ depending on whether the share of the expenditure for manufactured goods is less than or equal to $1 / 2$, or more than $1 / 2$.

[Figure 1 around here]

Figure 1 is a phase diagram for $\gamma \leq 1 / 2$ and corresponds to Cases 1 and 3. ${ }^{11}$ Both countries' economic structures are identical except for the initial endowments of capital stock,

\footnotetext{
${ }^{10}$ Note that even when $k_{i}$ approaches zero, $K_{i}$ continues to increase because the growth rate of $K_{i}$ is equal to the rate of profit and the rate of profit is always positive. The equations of manufacturing output, agricultural output, and terms of trade in each case are given in Appendix B, which is available on request. Case 3 is an extreme situation of Case 1: if we let $k_{2} \rightarrow 0$ in Case 1, then we obtain Case 3. In a similar way, Case 2 is an extreme situation of Case 4: if we let $k_{2} \rightarrow 0$, then we obtain Case 2.

${ }^{11}$ The coordinates of the points in figures 1 and 2 are given in Appendix $\mathrm{C}$, which is available on request.
} 
and accordingly, the phase diagram is symmetric with respect to the $45^{\circ}$ line. $\mathrm{E}_{1}$ is a steady state in which both countries diversify, corresponding to Case $1 . E_{2}$ is a steady state in which Home diversifies while Foreign asymptotically specializes in agriculture completely, ${ }^{12}$ corresponding to Case 3. $\mathrm{E}_{3}$ is a steady state in which Foreign diversifies while Home asymptotically specializes in agriculture completely. As figure 1 shows, $\mathrm{E}_{1}$ is a saddle point, and is thus, unstable. Accordingly, unless the initial conditions are exactly located either at $\mathrm{E}_{1}$ or on the $45^{\circ}$ line, both countries move toward either $E_{2}$ or $E_{3}$. This means that in the long run, one country diversifies while the other country asymptotically specializes in agriculture completely. For example, choose $S_{1}$ in figure 1 as the initial value. Note that $K_{1}>K_{2}$ at $S_{1}$. Then, Home diversifies while Foreign asymptotically specializes in agriculture completely in the long run.

[Figure 2 around here]

Figure 2 is a phase diagram for $\gamma>1 / 2$ and corresponds to Cases 1,2 , and $4 .{ }^{13}$ The phase diagram in this case is more complicated than that in $\gamma \leq 1 / 2 .{ }^{14}$

As with the case of $\gamma \leq 1 / 2, \mathrm{E}_{1}^{\prime}$ is a saddle point, and is thus, unstable. As the arrows in figure 2 show, both countries converge to either $\mathrm{E}_{2}^{\prime}$ or $\mathrm{E}_{3}^{\prime}$. $\mathrm{E}_{2}^{\prime}$ is a long-run equilibrium in which Home completely specializes in manufacturing while Foreign asymptotically specializes in agriculture completely, corresponding to Case 2. For example, choose $S_{2}$ in figure 2 as the initial value. Note that $K_{1}>K_{2}$ at $\mathrm{S}_{2}$. Then, Home completely specializes in manufacturing while Foreign asymptotically specializes in agriculture in the long run.

From the above analysis, we obtain the following proposition:

Proposition 1. Suppose that both countries differ in their initial endowments of capital stock. If the share of the expenditure for manufactured goods is less than or equal to $1 / 2$, then in the long-run equilibrium, one country diversifies while the other country asymptotically specializes in agriculture completely. If, in contrast, the share is more than $1 / 2$, then in the long-run equilibrium, one country completely specializes in manufacturing while the other country asymptotically specializes in agriculture completely.

Why do we obtain such results? When the share of the expenditure for manufactured goods is less than $1 / 2$, that is, the share of the expenditure for agricultural goods is more

\footnotetext{
${ }^{12}$ The word "asymptotically" implies that the agricultural output converges to zero but it never vanishes because we assume that Foreign's capital stock is strictly positive. For this, see also Christiaans (2008).

${ }^{13}$ For the explanation of Figure 2, see Appendix D, which is available on request.

${ }^{14}$ In our model, a regime switch occurs from diversification to complete specialization. That is, the systems of differential equations can change across boundaries, which yields a discontinuity in the right-hand sides of the differential equations. For the behavior of the system on the boundary, see Honkapohja and Ito (1983) and Marrewijk and Verbeek (1993).
} 
than $1 / 2$, the follower country alone cannot provide agricultural goods needed in the two countries, and consequently, there must be an agricultural sector in the other country, that is, the leader country has to diversify. On the other hand, when the share of the expenditure for manufactured goods is more than $1 / 2$, the leader country alone can provide manufactured goods needed in the two countries because of increasing returns to scale in manufacturing. ${ }^{15}$

\section{Comparison between free trade and autarky}

\subsection{Uneven development in terms of income and consumption}

Thus far, we conducted our analysis on the assumption that both countries are under free trade at the initial point in time. Now, we compare relative real income per capita $y_{1} / y_{2}$ and relative real consumption per capita $c_{1} / c_{2}$ under free trade and under autarky. Under both autarky and free trade, the BGP growth rates of $y_{i}$ and $c_{i}$ are equal, and consequently, $y_{1} / y_{2}$ and $c_{1} / c_{2}$ converge to constant values.

Under autarky, because $k_{1}^{*}=k_{2}^{*}$ along the BGP irrespective of the sizes of the initial capital stocks, both $y_{1} / y_{2}$ and $c_{1} / c_{2}$ converge to unity. Therefore, uneven development in terms of both income and consumption does not occur in the long run.

Under free trade, the size of $\gamma$ is important. In the following analysis, we consider the situation where the two countries start from $S_{1}$ and $S_{2}$ in figures 1 and 2, respectively.

When $\gamma \leq 1 / 2, y_{1} / y_{2}$ increases with time and converges to a constant value. Because $y_{1} / y_{2}>1$ from $k_{1}>k_{2}$ at initial point $S_{1}$, uneven development in terms of income will diverge. On the other hand, $c_{1} / c_{2}$ becomes $c_{1} / c_{2}=1$ immediately when switching from autarky to free trade. Therefore, uneven development in terms of consumption vanishes.

When $\gamma>1 / 2, y_{1} / y_{2}$ increases with time and converges to a constant value. Because $y_{1} / y_{2}>1$ from $k_{1}>k_{2}$ at initial point $S_{2}$, uneven development in terms of income will diverge. The path of $c_{1} / c_{2}$ is interesting. As long as both countries diversify, $c_{1} / c_{2}=1$ holds. However, from the time when Home completely specializes in manufacturing, that is, from the time when both countries pass through point $\mathrm{Q}$ in figure $2, c_{1} / c_{2}$ increases with time and converges to a constant value. Therefore, when $\gamma>1 / 2$, uneven development in terms of consumption will diverge.

Let us explain the reason why we obtain these results.

First, we explain uneven development in terms of consumption. Under free trade, the price levels of both countries are equalized. Thus, the real consumption per capita is given

\footnotetext{
${ }^{15} \mathrm{I}$ am indebted to an anonymous referee for pointing out this explanation. If the level of population differs between the two countries, then this difference in population too affects the results. Skott and Sethi (2000) also obtain such a relationship between expenditure patterns and trade patterns.
} 
by $c_{i}=w_{i} / p_{c}$, from which the relative consumption leads to $c_{1} / c_{2}=w_{1} / w_{2}$. When $\gamma \leq 1 / 2$, both countries diversify. This means that $w_{1}=w_{2}=1$, and consequently, we have $c_{1} / c_{2}=1$. When $\gamma>1 / 2$, both countries initially diversify. This means that $c_{1} / c_{2}=1$. However, after Home passes point $\mathrm{Q}$, and thus, begins to completely specialize in manufacturing, we have $w_{1}>1$, which implies that $c_{1} / c_{2}>1 .{ }^{16}$ Therefore, uneven development in terms of consumption will diverge when $\gamma>1 / 2$. This reasoning is basically the same as that obtained in Skott and Sethi (2000).

Second, we explain uneven development in terms of income.

When both countries diversify, we can express the relative income by using $k_{1}$ and $k_{2}$ as follows:

$$
y_{1} / y_{2}=\left\{1+\frac{2 \alpha \gamma}{(1-\alpha)\left[1+\left(k_{2} / k_{1}\right)^{\frac{\alpha+\beta}{\alpha}}\right]}\right\} /\left\{1+\frac{2 \alpha \gamma}{(1-\alpha)\left[1+\left(k_{1} / k_{2}\right)^{\frac{\alpha+\beta}{\alpha}}\right]}\right\} .
$$

In figure 1 , in the phase where both $k_{1}$ and $k_{2}$ increase, $k_{1}$ grows faster than $k_{2}$, which implies that $k_{2} / k_{1}$ decreases while $k_{1} / k_{2}$ increases. Accordingly, $y_{1} / y_{2}$ increases. In the phase where $k_{1}$ increases whereas $k_{2}$ decreases, $k_{2} / k_{1}$ decreases while $k_{1} / k_{2}$ increases. Accordingly, $y_{1} / y_{2}$ increases. Therefore, when $\gamma \leq 1 / 2, y_{1} / y_{2}$ increases, that is, uneven development in terms of income occurs. Even if $\gamma>1 / 2$, the same reasoning holds as long as both countries are located between $\mathrm{S}_{2}$ and $\mathrm{Q}$ in figure 2 .

When $\gamma>1 / 2$ and Home completely specializes in manufacturing while Foreign diversifies, that is, after point $\mathrm{Q}$, the relative income is given by

$$
y_{1} / y_{2}=\pi k_{1}^{\alpha+\beta} /\left[1+\alpha(1-\alpha)^{\frac{1-\alpha}{\alpha}} \pi^{\frac{1}{\alpha}} k_{2}^{\frac{\alpha+\beta}{\alpha}}\right] .
$$

After point Q, $k_{1}$ increases while $k_{2}$ decreases. The scale-adjusted terms of trade $\pi\left(k_{1}, k_{2}\right)$ are decreasing in both $k_{1}$ and $k_{2}$. Hence, the dynamics of $\pi$ are ambiguous. However, after enough time passes, both countries converge to $\mathrm{E}_{2}^{\prime}$ and the relative income at $\mathrm{E}_{2}^{\prime}$ is given by

$$
\lim _{t \rightarrow+\infty} y_{1} / y_{2}=\pi k_{1}^{\alpha+\beta}=\gamma /[(1-\alpha)(1-\gamma)]>1
$$

Given $\gamma>1 / 2$ and $0<\alpha<1$, we obtain $y_{1} / y_{2}>1$.

Summarizing the above analysis, we obtain the following two propositions:

Proposition 2. Suppose that uneven development is measured in terms of real income per capita. Then, the follower country cannot catch up with the leader country irrespective of the share of the expenditure for manufactured goods.

\footnotetext{
${ }^{16}$ For the reason why we obtain $w_{1}>1$ when Home completely specializes in manufacturing, see Appendix $\mathrm{E}$, which is available on request.
} 
Proposition 3. Suppose that uneven development is measured in terms of real consumption per capita. If the share of the expenditure for manufactured goods is less than or equal to $1 / 2$, then the follower country can catch up with the leader country. If, on the other hand, the share of the expenditure is more than $1 / 2$, then the follower country cannot catch up with the leader country. ${ }^{17}$

At the time when a country switches from autarky to free trade, real income increases and real consumption decreases or real income decreases and real consumption increases. These results originate in the differences in the propensity to save from wage income and from profit income. If we assume that a constant fraction of national income (wages plus profits) is saved like Solow (1956), real income and real consumption move proportionately, and hence, we can identify real income with real consumption. However, if the propensity to save differs according to income categories as in our model, we cannot identify real income with real consumption.

\subsection{Static and dynamic gains from trade}

The preceding subsection shows that when $\gamma>1 / 2$ under free trade, uneven development in terms of real consumption per capita occurs. However, even in this case, there exists a situation where Foreign is better off under free trade than under autarky. In the case where the relation between consumption under free trade and that under autarky is reversed with the passage of time, we can compare the integral of the present discounted values of real consumption per capita under free trade with that under autarky to judge which is better, free trade or autarky. If both countries switch from autarky to free trade at time zero, we can define the definite integral of $c(t)$ from $t=0$ to $t=T$ as follows: $W_{i}^{j}=\int_{0}^{T} c_{i}^{j}(t) \exp (-\rho t) d t$, $\rho>0, i=1,2, j=\mathrm{AT}, \mathrm{FT}$, where $\rho$ denotes the rate of time preference. The superscript $j$ denotes whether the economy is under autarky $(j=\mathrm{AT})$ or under free trade $(j=\mathrm{FT})$. For example, $W_{1}^{\mathrm{FT}}$ denotes the integral of the present discounted values of real consumption per capita in Home under free trade.

According to our analysis, which is larger, $W_{i}^{\mathrm{AT}}$ or $W_{i}^{\mathrm{FT}}$, is not uniquely determined. In other words, there exists a situation where free trade is better than autarky (i.e., $W_{i}^{\mathrm{FT}}>W_{i}^{\mathrm{AT}}$ ), and there also exists a situation where autarky is better than free trade (i.e., $W_{i}^{\mathrm{FT}}<W_{i}^{\mathrm{AT}}$ ). This occurs because at some point in time $t_{0}$, the sizes of $c_{i}^{\mathrm{FT}}(t)$ and $c_{i}^{\mathrm{AT}}(t)$ interchange.

\footnotetext{
${ }^{17}$ Similar results are obtained in Skott and Sethi (2000). They define uneven development in terms of real wage, which is identical to real consumption per capita. By introducing capital stock as a factor of production, we obtain different results with regard to uneven development in terms of between real consumption per capita and real income per capita.
} 
Moreover, their sizes also depend on $T$ and $\rho$. We explain why the sizes of $c_{i}^{\mathrm{FT}}(t)$ and $c_{i}^{\mathrm{AT}}(t)$ interchange.

Real consumption per capita $c$ is defined by dividing $w$ by $p_{c}$. Recall that $w=1$ when both countries diversify. From this, we obtain $c_{i}^{\mathrm{AT}}=1 / p_{c}^{\mathrm{AT}}$ and $c_{i}^{\mathrm{FT}}=1 / p_{c}^{\mathrm{FT}}$. Thus, the difference between consumption under autarky and that under free trade is reflected in the difference in the price level. In addition, considering that $p_{c}=p^{\gamma}, \pi=p L^{\phi-1}$, and $L^{\phi-1}$ are common to autarky and free trade, we can see that the difference between $c_{i}^{\mathrm{AT}}$ and $c_{i}^{\mathrm{FT}}$ when both countries diversify is reflected in the difference between $\pi^{\mathrm{AT}}$ and $\pi^{\mathrm{FT}}$. Note that when Home completely specializes in manufacturing, we have $c_{1}^{\mathrm{FT}}=w_{1} / p_{c}^{\mathrm{FT}}$, where $w_{1}>1$.

Along the BGP, $\pi$ is constant and can be explicitly calculated as follows:

$$
\begin{aligned}
& \pi^{\mathrm{AT}}=\gamma^{-\frac{\beta}{1-\alpha-\beta}} /\left\{(1-\alpha)[\alpha /(\phi n)]^{\frac{\alpha+\beta}{1-\alpha-\beta}}\right\}, \\
& \pi^{\mathrm{FT}}=\left\{\begin{array}{ll}
(2 \gamma)^{-\frac{\beta}{1-\alpha-\beta}} /\left\{(1-\alpha)[\alpha /(\phi n)]^{\frac{\alpha+\beta}{1-\alpha-\beta}}\right\} & \text { if } \gamma \leq 1 / 2 \\
{[\gamma /(1-\gamma)] /\left\{(1-\alpha)[\alpha /(\phi n)]^{\frac{\alpha+\beta}{1-\alpha-\beta}}\right\}} & \text { if } \gamma>1 / 2
\end{array} .\right.
\end{aligned}
$$

Comparing $\pi^{\mathrm{AT}}$ with $\pi^{\mathrm{FT}}$ when $\gamma \leq 1 / 2$, we certainly obtain $\pi^{\mathrm{FT}}<\pi^{\mathrm{AT}}$, which implies that $c_{i}^{\mathrm{FT}}>c_{i}^{\mathrm{AT}}$ along the BGP. When switching from autarky to free trade, Home has a comparative advantage in manufacturing, and consequently, $c_{1}^{\mathrm{FT}}<c_{1}^{\mathrm{AT}}$. However, $c_{1}^{\mathrm{FT}}>c_{2}^{\mathrm{AT}}$ in the long run. Therefore, Home experiences a conflict between the static and dynamic gains from trade. In Foreign, the relation $c_{2}^{\mathrm{FT}}>c_{2}^{\mathrm{AT}}$ continues to hold through time.

It is possible that $\pi^{\mathrm{FT}}>\pi^{\mathrm{AT}}$ when $\gamma>1 / 2 .{ }^{18}$ Along the BGP of Foreign that diversifies, we have $c_{2}^{\mathrm{FT}}<c_{2}^{\mathrm{AT}}$. When switching from autarky to free trade, Foreign has a comparative advantage in agriculture, and consequently, $c_{2}^{\mathrm{FT}}>c_{2}^{\mathrm{AT}}$. However, $c_{2}^{\mathrm{FT}}<c_{2}^{\mathrm{AT}}$ in the long run. Therefore, Foreign experiences conflict between the static and dynamic gains from trade. When $\gamma>1 / 2$, Home begins to completely specialize in manufacturing from some point in time, and consequently, $w>1$. After the complete specialization in manufacturing, Home always experiences $c_{1}^{\mathrm{FT}}>c_{1}^{\mathrm{AT}}$. However, when switching to free trade, Home has a comparative advantage in manufacturing, and consequently, $c_{1}^{\mathrm{FT}}<c_{1}^{\mathrm{AT}}$. Therefore, Home also experiences a conflict between the static and dynamic gains from trade.

We can summarize the above analysis as follows:

Proposition 4. Suppose that economic welfare is measured in terms of real consumption per capita. Even if autarky is better for the economy than free trade in the short run, there exists a situation where the economy is rendered better off under free trade in the long run because

\footnotetext{
${ }^{18}$ For example, if we use $\alpha=0.3, \beta=0.2, \gamma=0.6$, and $n=0.02$, we obtain $\pi^{\mathrm{FT}}>\pi^{\mathrm{AT}}$. Under perfect competition, the parameter $\alpha$ corresponds to the profit share, and therefore, $\alpha=0.3$ is reasonable. We owe the value of the extent of externality $\beta$ to the simulation of Graham and Temple (2006).
} 
of the dynamic gains from trade. In contrast, even iffree trade is better for the economy than autarky in the short run, there exists a situation where the economy is rendered worse off under free trade in the long run.

Proposition 5. Suppose that economic welfare is measured in terms of real consumption per capita. If the share of the expenditure for manufactured goods is more than $1 / 2$, then the follower country cannot catch up with the leader country. Nevertheless, there exists a situation where free trade is better for the follower country than autarky.

\section{Conclusions}

In this paper, we have investigated the relationship between trade and economic development using a two-country, non-scale growth model. In the model, we have assumed that two countries coexist with manufacturing and agricultural sectors and that both countries have identical economic structures except for the initial endowment of capital stock. Moreover, we have assumed that agricultural production is constant returns to scale while manufacturing production is increasing returns to scale. Depending on the share of the expenditure for manufactured goods, we obtain the following two situations: (1) if the share of the expenditure is less than or equal to $1 / 2$, then one country diversifies (produces both goods) while the other country asymptotically specializes in agriculture completely and (2) if the expenditure share is more than $1 / 2$, then one country completely specializes in manufacturing while the other country asymptotically specializes in agriculture completely.

In our model, regardless of the situation the economy belongs to (autarky or free trade) and regardless of the sector the economy specializes in (manufacturing or agriculture), the long-run growth rates of real income per capita and real consumption per capita in both countries are equalized.

Under autarky, the follower country can catch up with the leader country. Under free trade, on the other hand, whether or not the follower country can catch up with the leader country depends on two factors: the production patterns of the two countries and the measure of economic welfare used. We must note that even though the follower country cannot catch up with the leader country, it is possible that free trade is better for the follower country than autarky. 


\section{References}

Acemoglu, D., Ventura, J. (2002): 'The world income distribution', Quarterly Journal of Economics, 117 (2), pp. 659-694.

Arrow, K. J. (1962): 'The economic implications of learning by doing', Review of Economic Studies, 29 (3), pp. 155-173.

Baldwin, R. E. (1992): 'Measurable dynamic gains from trade', Journal of Political Economy, 100 (1), pp. 162-174.

Christiaans, T. (2004): 'Types of balanced growth', Economics Letters, 82 (2), pp. 253258.

Christiaans, T. (2008): 'International trade and industrialization in a non-scale model of economic growth', Structural Change and Economic Dynamics, 19 (3), pp. 221-236.

Chui, M., Levine, P., Murshed, S. M., Pearlman, J. (2002): 'North-South models of growth and trade', Journal of Economic Surveys, 16 (2), pp. 123-165.

Conway, P., Darity, W. A. (1991): 'Growth and trade with asymmetric returns to scale: a model for Nicholas Kaldor', Southern Economic Journal, 57 (3), pp. 745-759.

Dutt, A. K. (1996): 'Southern primary exports, technological change and uneven development', Cambridge Journal of Economics, 20 (1), pp. 73-89.

Dutt, A. K. (2002): 'Thirlwall's law and uneven development', Journal of Post Keynesian Economics, 24 (3), pp. 367-390.

Epstein, P., Howlett, P., Schulze, M.-S. (2007): 'Trade, convergence, and globalisation: the dynamics of international income distribution', Explorations in Economic History, 44 (1), pp. 100-113.

Felbermayr, G. J. (2007): 'Specialization on a technologically stagnant sector need not be bad for growth', Oxford Economic Papers, 59 (4), pp. 682-701.

Graham, B. S., Temple, J. R. W. (2006): 'Rich nations, poor nations: how much can multiple equilibria explain?' Journal of Economic Growth, 11 (1), pp. 5-41.

Honkapohja, S., Ito, T. (1983): 'Stability with regime switching', Journal of Economic Theory, 29 (1), pp. 22-48.

Jones, C. I. (1999): 'Growth: with or without scale effects?' American Economic Review, 89 (2), pp. 139-144.

Krugman, P. R. (1981): 'Trade, accumulation, and uneven development', Journal of Development Economics, 8 (2), pp. 149-161. 
Marrewijk, C. van., Verbeek, J. (1993): 'Disequilibrium growth theory in an international perspective', Oxford Economic Papers, 45 (2), pp. 311-331.

Mazumdar, J. (1996): 'Do static gains from trade lead to medium-run growth?' Journal of Political Economy, 104 (6), pp. 1328-1337.

Molana, H., Vines, D. (1989): 'North-South growth and the terms of trade: a model on Kaldorian lines', Economic Journal, 99 (396), pp. 443-453.

Quah, D. (1996): 'Twin peaks: growth and convergence in models of distribution dynamics', Economic Journal, 106 (437), pp. 1045-1055.

Redding, S. (1999): 'Dynamic comparative advantage and the welfare effects of trade', Oxford Economic Papers, 51 (1), pp. 13-39.

Sarkar, P. (2001): 'Technical progress and the North-South terms of trade', Review of Development Economics, 5 (3), pp. 433-443.

Sarkar, P. (2009): 'A centre-periphery framework on Kaldorian lines', Review of Political Economy, 21 (3), pp. 393-401.

Sasaki, H. (2008): 'International trade and industrialization with capital accumulation and skill acquisition', The Manchester School, 76 (4), pp. 464-486.

Sasaki, H. (2011): 'Population growth and north-south uneven development', Oxford Economic Papers, 63 (2), pp. 307-330.

Skott, P., Sethi, R. (2000): 'Uneven development and bilateral conflict', Metroeconomica, 51 (4), pp. 380-412.

Solow, R. M. (1956): 'A contribution to the theory of economic growth', Quarterly Journal of Economics, 70 (1), pp. 65-94.

Temple, J. (2005): 'Dual economy models: a primer for growth economists', The Manchester School, 73 (4), pp. 435-478.

Wong, K.-Y., Yip, C. K. (1999): 'Industrialization, economic growth, and international trade', Review of International Economics, 7 (3), pp. 522-540. 


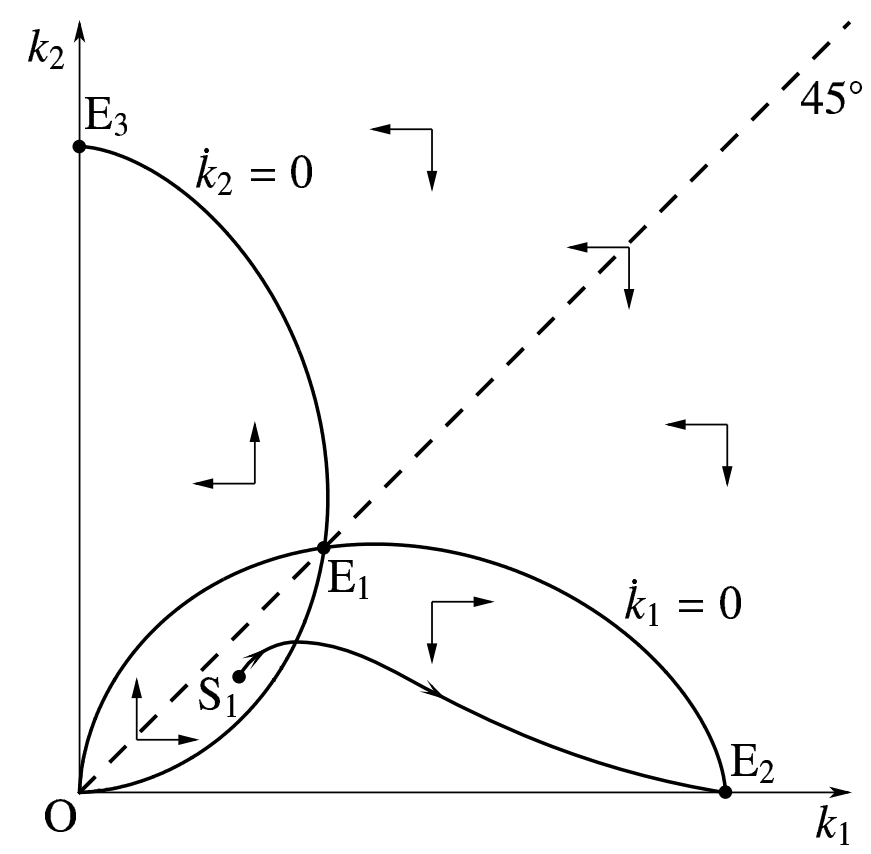

Figure 1: Phase diagram when the share of the expenditure for manufactured goods is less than or equal to $1 / 2$

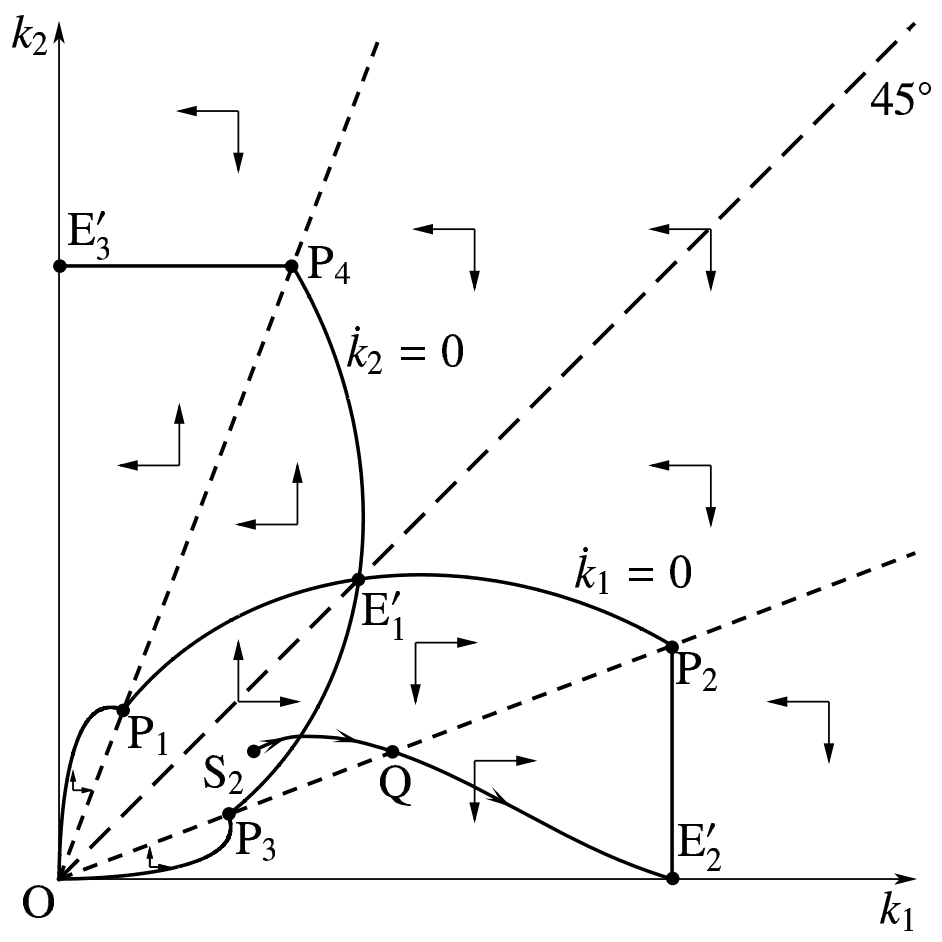

Figure 2: Phase diagram when the share of the expenditure for manufactured goods is more than $1 / 2$ 